ournal of Health Services Research \&

\title{
Evaluating the inclusivity of hospital wayfinding systems for people with diverse needs and abilities
}

\author{
Ido Morag', Ann Heylighen² and Liliane Pintelon ${ }^{3}$
}

\begin{abstract}
Objectives: Wayfinding in hospitals is a complex problem since patients, who are likely to be under stress, may have to navigate their way to multiple locations in the course of a single visit. While good wayfinding design can reduce stress, poor wayfinding can not only increase individuals' anxiety but also generate additional costs for the hospital due to: lost time among staff members who need to direct patients rather than concentrate on their designated task; missed appointments or delayed meetings; and additional security staff to ensure that patients do not enter restricted areas. We investigated to what extent a questionnaire, developed by collecting data about the subjective experiences of wayfinders with diverse needs and abilities, could uncover wayfinding problems in hospitals.

Methods: The methodology we developed involved four steps: creating an initial questionnaire based on the literature; customizing the questionnaire to a hospital environment; validating and verifying the questionnaire; and evaluating the questionnaire's added value at nine other hospitals.

Results: The questionnaire's generality and added value were demonstrated since many types of wayfinding problems were uncovered at the nine hospitals that other methods had overlooked or regarded as relatively unimportant. The research emphasizes the centrality and uniqueness of the wayfinder rather than that of the institute in determining what people need. Conclusion: Our findings can contribute to understanding wayfinding issues in hospitals and to sensitize designers to the needs and knowledge levels of wayfinders when designing hospitals.
\end{abstract}

\section{Keywords}

Evaluation methodology, hospital logistics, inclusive design, subjective data collection, wayfinding systems

\section{Introduction}

Successful wayfinding systems should provide people with the means to confirm that they are at the correct start or finish point; to identify their location and orient themselves within a building or an external space; to reinforce that they are travelling in the right direction; and to understand potential hazards and how to escape safely in an emergency. ${ }^{1-4}$ Since wayfinding was first introduced in 1960, there has been a development of theories, design principles, and methods aimed at supporting the creation of better wayfinding systems. While this has been beneficial, people continue to get lost in complex environments.

Designing wayfinding systems requires an approach that enables people to use efficiently their capabilities language, perception, knowledge, memory, and problemsolving abilities - in order to get from one location to another. Wayfinding relies on a succession of communication clues that include visual, audible, tactile, and olfactory elements. People need to be provided with a consistent set of indications.

In hospitals, wayfinding is important since patients, who are likely to be under stress, may have to navigate their way to multiple locations during a visit. ${ }^{5}$ Good wayfinding design promotes healing because it provides

\footnotetext{
'Department of Industrial Engineering and Management, Shenkar College of Engineering and Design, Ramat Gan, Israel

${ }^{2}$ Department of Architecture, KU Leuven (University of Leuven), Belgium ${ }^{3}$ Centre for Industrial Management/Traffic \& Infrastructure, KU Leuven (University of Leuven), Belgium

\section{Corresponding author:}

Ido Morag, Department of Industrial Engineering and Management, Shenkar College of Engineering and Design, Ramat Gan 52526, Israel.

Email: Idomorag@shenkar.ac.il
} 
people with a sense of control and empowerment, key factors in reducing stress, anxiety, and fear. ${ }^{6}$ Stressrelated problems, such as elevated blood pressure and headaches, are linked to wayfinding complexity. ${ }^{6,7}$ In addition, poor wayfinding can lead to additional costs through lost staff time, staff interrupting their activities to provide directions, lost business and dissatisfaction due to user frustration, missed appointments, and potential law suits arising from users wandering into areas that may be unsafe or off-limits. ${ }^{6,8}$ The need for good wayfinding systems becomes more acute as hospitals grow and expand. When new buildings/units are being added and routes are extensively being changed, the environment that patients and visitors encountered previously may be different. ${ }^{9}$

Wayfinding systems should communicate effectively to the broadest group possible, taking into account the range of sensory, physical, language, intellectual, and social and cultural background. ${ }^{5,10,11}$ Wayfinding systems should, therefore, be 'accessible to, and usable by, people with the widest range of abilities within the widest range of situations without the need for special adaptation or design'. ${ }^{12}$

Getting lost is an indication of a poor wayfinding system rather than inadequacy on the part of the wayfinder. ${ }^{3,7,13}$ Although signs may be well-designed, they may not provide simple enough cues. Recognizing both the consequences of inadequate wayfinding systems and increasing awareness for inclusive design has led to attempts to evaluate wayfinding in hospitals including: an evaluation based on advanced technology; ${ }^{14}$ developing a list of principles to evaluate systems; ${ }^{7}$ and developing principles that focus on inclusive design (particularly for people who are vision impaired). ${ }^{15}$

Data collection in hospital wayfinding has been concerned with people's behaviour rather than their experience. ${ }^{16}$ It has also focused on certain people - ablebodied individuals without impairments, ${ }^{17,18}$ those with dementia, ${ }^{19,20}$ or the elderly. ${ }^{21,22}$ Existing questionnaires include the Wayfinding System Audit Booklet (CRC); ${ }^{15}$ a checklist developed by The Center for Health Design; ${ }^{7}$ and one developed in a Thai hospital. ${ }^{14}$ However, to learn more there is a need for a questionnaire that will make it possible to locate problems and that presents information in the right form and at the right time to hospital users.

Our aim was to develop and evaluate a questionnaire that allows identifying the wayfinding problems faced by a diversity of hospital users. We addressed two questions: to what extent can a questionnaire that was developed in one hospital be used to uncover wayfinding problems both in that hospital and in other hospitals that base their wayfinding systems on static signage and staff assistance; and to what extent does the questionnaire have value in uncovering the wayfinding problems that people with different needs and abilities face in hospitals?

\section{Method}

Our study involved four stages: (1) creating an initial questionnaire based on the literature; (2) customizing the questionnaire to a hospital environment; (3) validating and verifying the questionnaire; and (4) evaluating the questionnaire's added value.

The questionnaire was developed at a university hospital and evaluated at nine other hospitals. These 10 hospitals varied as regards the spoken language; size (200-2000 beds); and structure and spatial characteristics (high buildings vs. multiple low buildings spread over a wide area). The university hospital was undergoing structural changes so people had to cope with route changes. Its wayfinding system was based on static signage consisting of directional text signs and colour-coded arrows and assistance from hospital staff. The scope of the study was limited to wayfinding between the main entrances of the hospitals and various destinations within them.

\section{Creating an initial questionnaire based on literature}

A literature review was performed using PubMed, Medline, IEEE Xplore ${ }^{\circledR}$, Embase and ScienceDirect databases, and Google Scholar. The inclusion criteria were: wayfinding in hospitals, inclusive wayfinding, wayfinding strategies, wayfinding usability, and wayfinding effectiveness.

Based on the review findings, an initial questionnaire was developed using Likert scaling in which the respondent is requested to specify his/her level of agreement to given statements on a symmetric agree-disagree scale. Since Likert scaling assumes that distances on each item are equal, the range captures the intensity of the respondent's feelings for a given statement. ${ }^{23}$

\section{Customizing the questionnaire to a hospital environment}

In order to create an inclusive questionnaire for hospital environments, we first participated ourselves in diverse wayfinding scenarios that various types of disabled individuals are apt to encounter, such as the use of a wheelchair to get from the main entrance to the oncology ward. Second, we observed how those visiting the hospital for the first time coped with wayfinding using existing directional information such as text displays and staff assistance. Third, we interviewed staff stationed at the hospital's main entrance to assist those entering. 


\section{Validating and verifying the questionnaire}

To improve the capability of the questionnaire we performed validation and verification processes, at the same university hospital, involving participants with a range of abilities. For ethical reasons we were not allowed to ask individuals who were involved in a medical procedure to participate. Accordingly, we used two approaches. First, newcomers leaving the hospital were asked to fill out the questionnaire. This approach of eliciting subjective experiences was based on the notion of 'expertise-by-experience', ${ }^{24}$ which highlights the value of people's embodied experience. Criteria for selecting participants included whether they were obviously impaired or dependent on assistance such as a wheelchair. In addition, a request for participants was submitted to the university service for disabled students as well as to the office dealing with international students in an effort to locate students who spoke a language other than the local one. The purpose of involving these students was to capture problems arising from cultural differences such as misunderstanding signs written in the local language or misinterpreting symbols. ${ }^{25}$ Accordingly, a bilingual questionnaire was developed - in the local language and in English. In total, 56 people completed the questionnaire (Table 1).

To assess whether the questionnaire could be used to uncover wayfinding problems at the hospital, participants were requested to comment whether the questionnaire related to all aspects of their wayfinding experience. $^{26}$ Following this, the questionnaire was modified. To determine whether the questionnaire was well-engineered and error-free, respondents were asked whether the questionnaire's structure was clear and easy to follow, whether the instructions informing respondents how to answer the questions were easy to understand; and whether the statements were well understood and unequivocal.

\section{Evaluating the questionnaire's added value}

The extent to which the questionnaire could be utilized to uncover wayfinding problems at hospitals with similar wayfinding systems was assessed at nine hospitals. The presence of a problem was based on a ranking of up to 3. Discussions between the researchers determined what issues were to be regarded as problems.

The extent the questionnaire, compared to other methods, uncovered wayfinding problems was assessed by comparison with a checklist derived from the Wayfinding System Audit Booklet (CRC). ${ }^{15}$ This checklist presented a comprehensive and detailed listing of the wayfinding difficulties that impaired individuals confront.
Table I. Participants' characteristics.

\begin{tabular}{llrr}
\hline Men & & 20 & $36 \%$ \\
Age (years) & & 36 & $64 \%$ \\
& $<30$ & 15 & $27 \%$ \\
& $30-39$ & 9 & $16 \%$ \\
& $40-49$ & 8 & $14 \%$ \\
& $50-59$ & 7 & $13 \%$ \\
& $60-69$ & 7 & $13 \%$ \\
& $70-79$ & 6 & $11 \%$ \\
Impairment & $>80$ & 4 & $6 \%$ \\
& None & 32 & $57 \%$ \\
& Visual & 2 & $43 \%$ \\
& Hearing & 4 & \\
& Physical & 13 & \\
& Learning disorder & 4 & \\
Mobility manner & Autism & 1 & \\
& Independent & 47 & $84 \%$ \\
& Wheelchair & 8 & $14 \%$ \\
Local language speaking & Full & 52 & $93 \%$ \\
& Noncort & 4 & $7 \%$ \\
\hline & & & \\
& & 1 &
\end{tabular}

\section{Results}

\section{Customizing the questionnaire to a hospital environment}

Following the questionnaire's customization, we modified the initial questionnaire. Examples include the addition of such statements as: 'The coloured arrows were effective in guiding you to arrive at several destinations in sequence' and modifying the statement 'The explanatory sheet clarifies how to get to the destination' to 'The hand-held map was useful in helping you go where you wanted to'.

\section{Questionnaire validation and verification}

Following the processes of validation and verification, additional modifications to the questionnaire were made. For example, the statement 'The hallways were quiet and it was easy to hear what was said' was added following the experience of an individual with autism. The statement 'The help desk was visible and easy to find' was added following the experience of a visually impaired person. The final version of the questionnaire can be found in online Appendix 1.

\section{Validating the questionnaire's generality for other hospitals}

Table 2 presents an overview of problem types identified at nine hospitals using the questionnaire. The difficulties 
at the hospital's main entrance received emphasis in the questionnaire, including the information displayed on the directional signs (e.g. How easy was it to locate the required destination using the presented information?) and the assistance of the hospital staff (e.g. How easy was it to communicate with them?).

Difficulties at the entrance were reported by almost all participants (18 of the 60 statements in the questionnaire captured difficulties at this stage). The first stage of wayfinding is perceived to have a significant impact on their overall ability to cope. While the issue of directional signs is well studied in the literature, ${ }^{4,13}$ the necessity of staff assistance is rarely discussed. Specifically, the assisting staff's visibility, accessibility, and willingness occupy 10 of the 18 entrance-related statements above.

The participation of disabled people played an important role in uncovering problems that are characterized by specific variations, such as lighting and acoustic suitability. For example, visually impaired individuals reported that the lighting in hallways was inadequate for lip reading and for following directional signs. Comments on acoustic unsuitability were also noted by some with vision impairment since their reduced vision frequently forces them to utilize their hearing to collect supplementary information.

Another important topic that emerged referred to the use of the elevators (11 out of the 60 statements). Among the difficulties were the forces that those suffering from muscle laxity needed to activate the controls and lack of audible announcements when the elevator arrived at the desired floor. This lack included the failure to announce the number of the floor and what units and services were available at the desired floor.

With regard to hallways, mobility-impaired people commented on lack of banisters along routes and the necessity of having doors open automatically. Individuals with learning disorders and autism raised the need for maintaining a similarity in the interior spaces at different levels.

The use of directional signs was also commented on. Typical topics included recognizing and understanding graphic icons and symbols. All the participants in the study complained about the need to remember the colour of the relevant arrow along the route. This was particularly annoying when the colours were similar (beige and grey, for instance) and there was no verbal indication as to what the colour of the arrow was. For many users the signs as to whether or not they had arrived at their destination were not clear and they had to ask staff members to confirm that they had arrived at the proper place.

All participants indicated that they managed to reach a single destination. Reaching multiple destinations in sequence (e.g. collecting blood samples from the

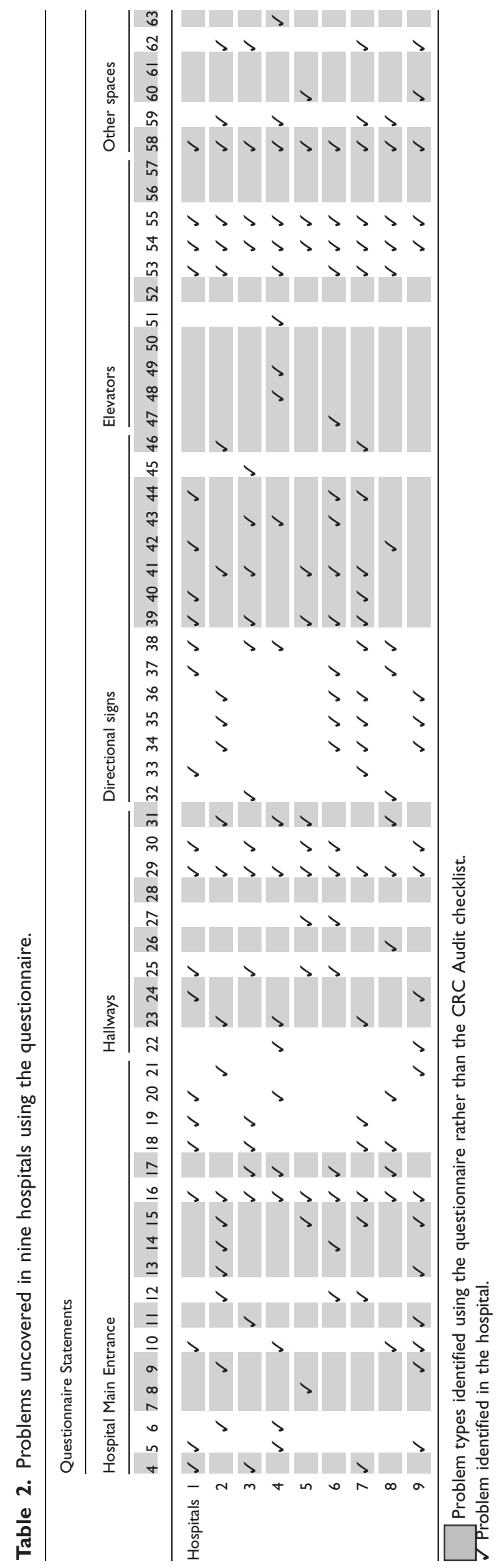


laboratory and bringing them to the oncology ward) was found to be complicated and time-consuming since the participants were not able to use the colored arrows to get from one destination to another. Reaching sequential destinations forced them to return to the main entrance following each destination and to start a new wayfinding to the next one.

\section{Evaluating the questionnaire's added value compared to the CRC Audit booklet}

To evaluate the ability of the questionnaire to uncover wayfinding problems that the CRC either disregards or regards with a minor attention, both evaluation tools were used at all nine hospitals. A comparison between their outcomes can be seen in Table 2 with the shaded columns indicating problem types that were identified exclusively by the new questionnaire.

\section{Discussion}

\section{Main findings}

Although the questionnaire was developed in one hospital, it turned out to be thorough and comprehensive enough to uncover problems at nine other hospitals that use a similar type of wayfinding system. This was achieved despite the substantial differences between the hospitals. This generality can be attributed to the multiple and complementary data collection methods used in developing the questionnaire.

The added value of the questionnaire is reflected in the different types of problems that were uncovered by the questionnaire, but which the CRC disregards or devotes marginal attention. We assume that this added value stems from the questionnaire's focus on inclusiveness. This made it possible to comprehensively analyze wayfinding systems in a way that reflected the problems that people confront. The clear and explicit phrasing of the questionnaire's statements, in accordance with the wayfinder's subjective experience, brought into focus problems that the CRC was unable to discern.

\section{Limitations}

The questionnaire scope refers to the inside of the hospitals although much of the stress and the anxiety may be caused at an earlier stage (e.g. when parking or finding the appropriate entrance to the hospital). In addition, although the questionnaire focused on inclusiveness, only $43 \%$ of the participants were impaired. However, we may assume that some participants may have had non-visible impairments of a mental or cognitive nature.
In addition, while we were concerned with developing a questionnaire to ensure comprehensiveness and thoroughness, this strength could possibly be regarded as an obstacle by participants rushing to arrive at an appointment or for those with a visual impairment.

Some researchers differentiate between wayfinding concepts (spatial reasoning, path planning from memory, etc.) and locomotion (steering, obstacle avoidance, etc.). ${ }^{27}$ Although the questionnaire centers on wayfinding, some of the statements may be more accurately associated with locomotion. These latter statements were nonetheless included since the issues they represent were raised by the participants to be contributing elements in their ability to cope with a wayfinding task.

\section{Future directions for evaluating wayfinding systems}

Due to the complexity of wayfinding in hospitals undergoing growth and expansion, different technologies are being developed to assist people. Beyond the use of static signage, spatial cues such as arrows, numeric encoding and color coding, and the guidance of hospital staff, there is increasing implementation of customized and adaptive technologies, which produce personal wayfinding guidance specifically tailored to meet a wayfinder's needs. For example, a system might direct a person to his or her destination using arrows projected on the floor. ${ }^{28}$ Other systems might include dynamic displays along the route, presenting relevant information in accordance with people's specific needs, such as large fonts for those with vision impairments or in English for those who do not speak the local language. ${ }^{25}$ The research on harnessing such technologies to cope with wayfinding is in its initial steps and should be further evaluated. In addition, efforts should be directed at studying wayfinding outside hospitals as well as on sites within the hospital such as the outpatient clinics.

Questionnaire-based findings support the possibility of developing a methodology that can be used to develop guidelines for other hospitals in the future. Implementing the questionnaire uncovered additional types of problems and highlighted major ones, reinforcing the perception that wayfinding is a complex problem that should be studied using multidisciplinary knowledge and experience.

\section{Acknowledgements}

The authors thank Céline van Loon and Annelies Eerdekens for their help in developing the wayfinding questionnaire.

\section{Declaration of conflicting interests}

The author(s) declared no potential conflicts of interest with respect to the research, authorship, and/or publication of this article. 


\section{Funding}

The research was supported by the Erasmus Mundus Action II fellowship (Israel 2013-2436).

\section{References}

1. Lynch K. The image of the city. Vol 11, Cambridge, MA: MIT Press, 1960.

2. National Institute on Disability, Independent Living, and Rehabilitation Research (NIDILRR), http://www.acl.gov/programs/NIDILRR/ (2016, accessed 24 March 2016).

3. Baskaya A, Wilson C and Ozcan Y. Wayfinding in an unfamiliar environment. Different spatial settings of two polyclinics. Environ Behav 2004; 3: 839-867.

4. Gibson D. The wayfinding handbook: information design for public places. New York: Princeton Architectural Press, 2009.

5. Arthur $\mathrm{P}$ and Passini R. Wayfinding: people, signs and architecture. New York: McGraw-Hill, 1992.

6. Carpman JR and Grant MA. Design that cares: planning health facilities for patients and visitors, 2nd ed. Chicago: American Hospital Publishing Inc, 2001.

7. Huelat BJ. Wayfinding: design for understanding. A position paper for the environmental standards council of the Center for Health Design. Chicago. The Center for Health Design. https://www.healthdesign.org/sites/default/files/ WayfindingPositionPaper.pdf (2007, accessed 24 March 2016).

8. Sadler BL, DuBose J and Zimring CM. The business case for building better hospitals through evidence-based design. Health Environ Res Des 2008; 1: 22-39.

9. Garling T, Book A and Lindberg E. Spatial orientation and wayfinding in the designed environment: a conceptual analysis and some suggestions for post occupancy evaluation. J Archit Plann Res 1986; 3: $55-64$.

10. Weber LS and Charlton JL. Wayfinding in older adults. Clin Gerontol 2001; 23: 168-172.

11. Levine D. Universal Design New York, Center for Inclusive Design and Environmental Access, University of Buffalo. The State University of New York at Buffalo, http://ada.osu.edu/designud/UD $\% 20 \mathrm{New} \% 20$ York $\%$ 202.pdf (2003, accessed 24 March 2016).

12. BS 7000-6:2005. Design management systems. Managing inclusive design. Guide, http://shop.bsigroup.com/Product Detail/?pid $=000000000030142267$ (accessed 24 March 2016).

13. Passini RE. Wayfinding in architecture (Environmental design series V. 4). Somerset, NJ: John Wiley \& Sons Inc, 1984 .

14. Mclaughlin J, McNeil BB and Sebald SE. Addressing wayfinding at Bumrungrad Hospital, citeseerx.ist.psu. edu/viewdoc/download?doi=10.1.1.617.5565\&rep=rep1 $\&$ type $=$ pdf $(2005)$.
15. Apelt R, Crawford $\mathbf{J}$ and Hogan D. Wayfinding system audit. Cooperative Research Centre for Construction Innovation, http://www.signdesignsociety.co.uk/images/ Knowledgebase/CRC0001_CRC_Wayfinding_Audit.pdf (2007, accessed 24 March 2016).

16. Rooke CN, Koskela L and Tzortzopoulos P. Achieving a lean wayfinding system in complex hospital environments: design and through-life management. In: IGLC18 proceedings of the conference of safety, Quality and Environment, 2010.

17. Gray WD, Sims CR, Fu WT, et al. The soft constraints hypothesis: a rational analysis approach to resource allocation for interactive behavior. Psychol Rev 2006; 113: 461-482.

18. Holscher C, Buchner SJ, Meilinger T, et al. Adaptivity of wayfinding strategies in a multi-building ensemble: the effects of spatial structure, task requirements, and metric information. J Environ Psychol 2009; 29: 208-219.

19. Passini RE, Rainville C, Marchand N, et al. Wayfinding in dementia of the Alzheimer type: planning abilities. $J$ Clin Exp Neuropsychol 1995; 17: 820-832.

20. Letts L, Minezes J, Edwards M, et al. Effectiveness of interventions designed to modify and maintain perceptual abilities in people with Alzheimer's disease and related dementias. Am J Occup Ther 2011; 65: 505-513.

21. Morganti F and Giuseppe R. Spatial orientation decline in elderly population. ICVR ' 11 Proceedings of the International Conference on Virtual Rehabilitation, http://ieeexplore.ieee.org/stamp/stamp.jsp?tp=\&arnumber =5971848 (2011, accessed 24 March 2016).

22. Harris MA and Wolbers T. How age-related strategy switching deficits affect wayfinding in complex environments. Neurobiol Aging 2014; 35: 1095-1102.

23. Burns RB and Burns RA. Business research methods and statistics using SPSS. London: SAGE, 2008.

24. Heylighen A. Inclusive built heritage as a matter of concern: a field experiment. In: Langdon P, Clarkson P, Robinson $\mathrm{P}$, et al. (eds) Designing inclusive systems. London: Springer-Verlag, 2012.

25. Hashim KJ, Alkaabi M and Bharwani S. Interpretation of way-finding healthcare symbols by a multicultural population: navigation signage design for global. Appl Ergon 2013; 45: 503-509.

26. IEEE Guide-Adoption of the Project Management Institute $\left(\mathrm{PMI}^{\circledR}\right)$ Standard. A guide to the project management body of knowledge (PMBOK ${ }^{\circledR}$ Guide), 4th ed. 2011.

27. Shah P and Miyake A. The Cambridge handbook of visuospatial thinking. Cambridge: Cambridge University Press, 2005.

28. IBM Research. Everywhere Displays project, http:// www.research.ibm.com/people/p/pinhanez/cp_research_ ed.htm (2004, accessed 24 March 2016). 